\title{
Julio Arboleda y su "Gonzalo de Oyón"
}

\begin{abstract}
A hablar Menéndez y Pelayo - con especial simpatía y A encendido entusiasmo, ya que no con mucha originalidad-de don Julio Arboleda y de su obra poética, nos dice que este colombiano, "espíritu de rara distinción", fue "el tipo más caballeroso y aristocrático que en los sangrientos anales de la democracia americana pueda encontrarse"; que "su brillante existencia" se parecí a las de los guerreros soldados del siglo de oro español, "salvo que a Arboleda no fuele concedido morir con la muerte de los bravos, como a Garcilaso, a la luz del sol, asaltando una plaza de armas, como a su valor cuadraba, sino que cayó en una emboscada nocturna"; que sus poesías sueltas "son casi todas de amor o de política, impregnadas las más de suavísima ternura, de una como devoción petrarquesca y espiritualizada; rebosando las otras de férvida indignación, entusiasmo bélico, odio y execración a toda tiranía", por estar hechas de versos "que huelen a pólvora" y semejan "rugidos de león más que obras de arte"; y que su gloria literaria se cifra principalmente en su Gonzalo de Oyón, que, "incompleto y todo, es el más notable ensayo de la poesía americana en la narración épica", si bien lo vence, "en pormenores de dicción y de estilo", la versión que del Orlando enamorado hizo don Andrés Bello.

Con tal introducción, escrita en 1893 por el reconocido "príncipe" de los críticos españoles, -bella en su concisión, y certera y precisa aun a pesar del dejo de parcialidad "clásica" y peninsular que en ella se siente-imposible sería no querer estudiar la personalidad de don Julio Arboleda y no
\end{abstract}


experimentar el deseo irresistible de valorizar hoy su Gonzalo de Oyón, poema tan poco conocido en las últimas "promociones" literarias, con todo y tener el puesto tan alto que a él le asignó quien la escribió.

\section{$* * *$}

Nos cuenta don Miguel Antonio Caro que era don Julio Arboleda vástago de hidalga familia antigua. Ya en 1676, el Maestro ecuatoriano Jacinto de Hevia, en su Ramillete de varias flores poéticas (Madrid, Nicolás de Xamares), que dedicó al Licenciado don Pedro de Arboleda y Salazar, afirma que "Bien sabe el mundo que después de haber los Arboledas ilustrado en Francia famosos varones, pasaron a España", para venir más tarde a la ciudad colombiana de Popayán, donde se emparentaron con otras familias ilustres, los Pombos, los Ulloas, los Caldas, los Valencias...

El mismo don Julio dice que "nació en un desierto, en medio de las selvas incultas que orlan el mar Pacífico", pues sus padres, don Rafael Arboleda y doña Matilde Pombo y O'Donell -descendiente ésta de ilustre familia irlandesa de guerreros y tribunos-, al verse perseguidos por las fuerzas españolas realistas que intentaban recuperar para Fernando VII el dominio de la América revolucionada habian huído de Popayán y se habían refugiado en su hacienda de Timbiquí, situada en las márgenes salvajes del río Telembí.

Allí nació, el 9 de julio de 1817 -de junio, según dice Gustavo Otero Muñoz-el poeta soldado. ¡Romántico comienzo de una romántica existencia rica en episodios y aventuras, brillante y seductora!

No fué don Julio a la escuela. Sus primeras letras las hizo en su casa, y "con la leche mamó los sentimientos cristianos" que en su agitada y noble vida "siempre se honró de profesar". Su abuela materna, doña Beatriz O'Donell, le enseñó el francés, y su abuelo, don Manuel Antonio de Pombo, le dió lecciones de latinidad, de castellano y de 'geometría. En 1830, fue llevado por su padre a Inglaterra, y en Londres continuó sus estudios y se "hizo dueño de la lengua inglesa hasta el punto de escribir en ella con propiedad y atildamien- 
to". Tan rápidos fueron los adelantos del joven payanés, según Torres Caicedo, "que a la edad de catorce años ya era contado entre los más distinguidos corresponsales del $M e-$ chanic's Magazine, periódico científico que se publicaba en Londres, y en cuyas columnas se encuentran interesantes producciones" suyas.

En la Universidad de Londres obtuvo Arboleda el grado de Bachiller en Artes. Estuvo luego en Francia y en Italia, y regresó a Popayán en 1838, y en su Universidad del Cauca estudió leyes y dictó cursos de literatura, en una época de violentas sacudidas políticas en que se desangraba la Nueva Granada, recientemente independizada de la Monarquía española.

En Popayán, don Julio y sus amigos, "la flor de la juventud payanés", según el señor Caro, fundaron una sociedad intitulada "Filológica", que pronto hizo sentir su influencia "primero en las elecciones" y después "en el conflicto de las urnas"... Esa sociedad de "filólogos"... luchaba pues contra la anarquía de los tiempos y buscaba la restauración de las clases dirigentes del país amenazadas por el pueblo en armas. Y don Julio, espíritu vehemente, dominador y fiero, se vió envuelto en una de las "más desastrosas" guerras civiles que "han asolado a la Nueva Granada". Abandonando su casa y su fortuna, y aun a la bella dama prometida a quien entonces cortejaba y con quien se casó más tarde (en 1842), Arboleda empuñó la espada del guerrero, luchó con habilidad, gallardía e "intrepidez generosa", y terminó su primera campaña con el título de Teniente Coronel, habiéndola comenzado con el de Teniente. Sirvió sin recibir sueldos ni recompensas, y perdió gran parte de su fortuna, que le fué confiscada por sus enemigos. Así pudo exclamar: "Yo no he ido a vender mi vida por una paga vil, sino a rescatar con mi sangre y con mis propiédades la libertad atacada por la anarquía!"

Para 1843, terminada la guerra, Arboleda se dedicó a sus negocios particulares y a las labores del campo, $y$, en el retiro de su hacienda, puso manos a su Gonzalo de Oyón y escribió algunos cantos del poema. "que miraba entonces con entrañable cariño, como a hijo mimado de su entendimiento".

Fué luego al Congreso, como representante. Su apari- 
ción, dice José María Samper, como orador parlamentario, "fué deslumbradora". Incisivo, ágil, correcto de ademán y de palabra, variado en su elocuencia, erudito, vigoroso, irónico y sarcástico a veces, $\mathrm{y}$ otras agresivo, cortante y patético, don Julio era "arrebatador"... Inquieto y batallador, y nada propenso a la adhesión incondicional, siendo conservador y católico se afilió a la causa de la oposición parlamentaria, y se mostró como "el más poderoso y temible acusador de los Jesuitas, influído" por las lecturas de Michelet y de Quinet. En 1848 publicó contra ellos su famoso y virulento panfleto Los Jesuitas..., "movido por una convicción errónea, pero sincera", que más tarde habría de cambiar.

De vuelta en su hacienda del Cauca, Arboleda se dió a escribir para los periódicos contra los abusos sociales y las ideas positivistas que defendían sus enemigos, y por ello fué puesto en la cárcel, hecho éste que le inspiró dos de sus más valientes y briosas poesías, "Estoy en la cárcel" y "Al Congreso granadino", únicas en la literatura de su patria.

En 1851, Arboleda; que era enemigo de los "revolucionarios", se hizo revolucionario: el gobierno "liberal" de entonces predicaba la lucha de clases, y la fomentaba, y Arboleda era amigo de la ley y del "orden"... Destrozadas sus fuerzas, el guerrero poeta se asiló en el Perú hasta principios de 1853. En Lima se ganó la vida dictando lecciones de literatura y escribiendo para la prensa local.

En 1854 ocurrió algo un tanto insólito en la historia de Colombia: el General José María Melo -antiguo soldado de la Guerra de la Independencia y aventurero de odiosa memoria en los anales patrios-, por medio de un atrevido golpe de cuartel se hizo dictador y jefe supremo de la república y quiso explotarla a su antojo. Contra el usurpador se levantaron los legitimistas de los dos partidos tradicionales de Colombia, y Arboleda, "siempre impaciente y ávido de servir y de ejercitar su bravura personal", regresó del destierro y se puso ál frente de un ejército con el cual luchó hasta vencer y restaurar el orden y la ley. En seguida se fué a vivir a $\mathrm{Pa}$ rís, con el objeto de educar a sus hijos. Mas no había de ser larga su permanencia en la capital francesa. Una nueva gue- 
rra civil, que duró dos años, estalló en la anárquica y joven república que él amaba tanto y que servía con eficacia ejemplar. Don Julio volvió a la Nueva Granada en 1860, y después de larga y hazañosa campaña, en la cual desplegó todos los recursos de su genio militar, -astucia, valor, actividad, dón de mando, audacia, resistencia, agilidad y conocimientos-y logró memorables triunfos y "la gloria de los caudiIlos invictos", cayó asesinado, en 1862, en las ominosas Montañas de Berruecos, cerca al sitio donde años antes $y$ en circunstancias semejantes, había caído el puro y magnánimo don Antonio José de Sucre, Mariscal de Ayacucho y Lugarteniente de Bolívar.

Asesinado cobardemente cayó don Julio, a los cuarenta y cinco años de edad, en la plenitud de su preciosa existencia, y después de haber luchado sin cesar durante veìnticuatro, como guerrero, como orador parlamentario, como escritor, como poeta.

Y murió tal y como él mismo lo había presentido, y aun anunciado años antes en alguno de sus escritos! Extraño poder intuitivo el de este varón singular: aun el sitio donde había de caer lo había él predicho!

No murió don Julio, como Garcilaso, a plena luz y en el asalto de una plaza de armas y como correspondía a su valor. Murió como un mártir de la democracia, como correspondía a su virtud ciudadana, como Lincoln, como Jaurès... .

En los turbulentos anales de su patria, don Julio brilla con luz propia: lívar.

Se ha dicho de él que, como guerrero, es émulo de Bo-

Como orador, se distinguió en tierras de oradores.

Como caballero, para hallarle pares es preciso leer historias antiguas o leer romances medievales...

Como poeta... conviene ahora analizar y valorizar su obra.

$$
* * *
$$

Ya se han citado en este estudio las palabras de Menén- dez y Pelayo en relación con la obra poética de Julio Ar- 
boleda, palabras que en parte repiten más tarde-eco de ecos-Isaac J. Barrera, en el Ecuador, y Calixto Oyuela en la Argentina... Veamos lo que dicen otros críticos españoles $\mathrm{y}$ americanos.

Cejador y Frauca - esta vez quizás escribiendo sin olvidarse de que el poeta payanés fué autor de un brioso panfleto contra los miembros de la Orden à que aquél pertenecí-, dice sin reparos: Arboleda "hizo poesías amorosas (1840-1850), otras satíricas de política bélica contra la tiranía, y el poema no acabado Gonzalo de Oyón (1851), conocido por borradores, de mucha fuerza épica y gallardo decir, por el estilo del Moro Expósito, del Duque de Rivas, y del poema de Granada, de Zorrilla, poetas con los cuales se encadena Arboleda, bien que diste infinito de ellos, por ser un verdadero clásico de la escuela del Siglo XVIII, de no muy rica fantasía ni sensibilidad. Dijérase un erudito que rima ideas prosaicas y frías". Cita además Cejador y Frauca la opinión de Menéndez y Pelayo según la cual el Gonzalo de Oyón es "el más notable ensayo de la poesía americana en la narración épica", y concluye: "No estoy conforme con el Maestro: Tabaré se levanta muy por cima de este poema, que es demasiado clásico, frío y seco, comparado con el de Zorrilla de San Martín y aun con La cautiva, de Echeverría".

Luis Alberto Sánchez, en cambio, afirma - en ligerísimo comentario- que Arboleda "fué el prototipo del romanticismo colombiano", hombre "de un temperamento grandemente emotivo" y "adversario desde joven de don José Eusebio Caro y de su escuela política y literaria". Admite Sánchez que Arboleda hiciera uso del tema indigenista, pero sólo "en el sentido descriptivo y externo en que lo cultivó Echeverría", y termina sosteniendo que "la naturaleza merece continuas estrofas de Arboleda y el Tequendama parece como su numen tutelar".

¿Es Arboleda un poeta clásico, amigo de rimar ideas frías y prosaicas, como quiere Cejador y Frauca, o es el prototipo del romanticismo colombiano, a quien inspira el Tequendama como su numen tutelar, tal y como nos lo dice Sánchez?

Con perdón de los dos eruditos, el peninsular y el perua- 
no, diremos nosotros: No fué Arboleda adversario de la escuela política de José Eusebio Caro - los dos fueron íntimos amigos, conservadores y católicos defensores de la misma causa-, ni tampoco de su escuela literaria, ya que el cantor de "En boca del último Inca", "En alta mar", etc., don José Eusebio, fué romántico hasta los tuétanos, y su poesía lo es en forma y contenido; y si es cierto que Arboleda canta a menudo la naturaleza, su "numen" no fué el famoso Salto del Tequendama... sino el río Cauca, $\mathrm{y}$ su Valle y las montañas y mesetas que lo circundan. ¿Frío rimador el autor de "Estoy en la cárcel", "Al Congreso granadino", Gonzalo de Oyón?.. ¿ ¿Frío y "clásico" el vehemente poeta payanés cuyos versos le parecieron a Menéndez y Pelayo rugidos de león y le olieron a pólvora, unas veces, y otras lo arrullaron con suaves ternuras que recuerdan a Petrarca y logran íntima y noble idealidad?

Cejador y Frauca, y Sánchez, no debieron de leer con cuidado toda la obra de don Julio... Bueno es que consideremos otras opiniones.

Gómez Restrepo - tan justo y penetrante siempre en sus juicios literarios-dice que Arboleda no era "un lírico por el estilo de Caro, sino un poeta épico y objetivo"; que "perdura en la forma de sus versos algo de la tradición clásica del siglo anterior"... "pero el espíritu de su poesía es francamente romántico"; que si sus descripciones del paisaje caucano "ofrecen a veces la armonía de luces y colores del arte clásico, otras tienen la grandiosidad abrupta y trágica, los violentos contrastes de líneas y de sombras propias de la nueva escuela" (la romántica); y que si de su obra "se tienen en cuenta los grandes cuadros, aquellos que habrían podido servir de tema al pincel fantástico de Gustavo Dorée, debe reconocerse con justicia que un poeta de esa imaginación, de ese brío, de esa arrogancia de dicción, de ese arranque varonil y magnífico, no es indigno de figurar en el coro que ilustran los autores de El Moro Expósito y de Granada". (Se ve que esta opinión de Gómez Restrepo puso en guardia a Cejador y Frauca, ¿verdad?... ¿Pero no era para tanto!)

Finalmente, don Miguel Antonio Caro, editor de las Poesías de Arboleda, humanista y crítico literario de alto vuelo 
-humanista y crítico sin rival en la América hispana-, nos dice:

"Arboleda era un gran improvisador, escribía muy a la ligera, pero luego, por amor y respeto al arte, corregia una y muchas veces.

"Formó su gusto principalmente en la lectura de los poetas italianos, a que era aficionadísimo, y de los ingleses, que conocía muy bien; $y$ en sus versos se mezclan en raro concierto la galanura, viveza y calor meridionales, con cierta misantropía nebulosa del Norte". El poeta "es original en el estilo, sin ser revolucionario en el lenguaje"; es, "como conviene, fogoso y enérgico, ora describa un arranque de desesperación, ora un riña sangrienta"; y a veces su poesía "corre con ligereza $\dot{y}$ gracia, o se desliza con maravillosa blandura".

Así, cual lo afirman Caro y Gómez Restrepo, es la poesía del guerrero payanés.

Don Julio Arboleda - su temperamento, su vida y el ambiente en que nació, vivió y actuó-, por una parte, y por otra su obra poética, se compenetran tanto, que en realidad constituyen una admirable ecuación, casi una identidad: nada falta en ninguno de sus dos términos para hacerla perfecta, ni siquiera el carácter fragmentario que los distingue.

Vástago de ilustre familia hecha al lujo y al refinamiento de una ciudad antes opulenta y culta, don Julio nació en medio de una selva tropical: $\mathrm{Su}$ poesía, de clásicas formas refinadas, es a menudo desigual, tumultuosa, ardiente, o suave y delicada...

Hijo de padres ricos y sedentarios, don Julio fué inquieto, arrebatado, diligente: Así son sus poesías políticas...

Hombre nacido para la meditación encumbrada y el razonamiento lógico, en el sosiego del bufete, la cátedra o el templo, vivió mucho al calor de las fogatas de guerra, y tuvo que improvisarlo todo, sus huestes indisciplinadas, sus discursos parlamentarios, sus poemas de lucha social...

Educado en Europa, actuó en una nación joven y anárquica, y afrontó continuamente el peligro, en lucha contra la naturaleza, contra los hombres, contra las ideas que amenazaban la vida misma de las que él había aprendido en sus vie- 
jos centros culturales: Su poesía - de contenido europeo en cuanto a sus ideas directrices-es libre y aun contradictoria, y rebosa de americanidad...

Lector enamorado de los poemas renacentistas italianos y de los clásicos ingleses, don Julio tuvo que escribir, entre batalla y batalla, y a menudo mientras viajaba por valles $\mathrm{y}$ montañas y bosques y praderas, hallando inspiración en tierras vírgenes habitadas por una raza en gestación, híbrida, agitada e informe: Su poesía le hace eco a la de Ariosto y Petrarca, y Milton y Byron... pero sus temas son americanos!

Político de altas prendas, y caudillo invicto digno de la consagración, y digno también de lograr una vejez rodeada del respeto y el halago populares, don Julio murió asesinado alevosamente, en plena juventud, en el seno tenebroso y agorero de una montaña inmensa: Su mejor poema, Gonzalo de Oyón, de simbolismo tan sugerente y arrebatador, quedó también mutilado por el pueblo para quien lo escribió...

Romántica en su esencia fué la existencia luminosa del vate payanés: se orientó siempre hacia los valores eternos, -la justicia, el amor, la libertad-, sin alcanzar ninguno de ellos: Así su poesía...

En espíritu su arte es romántico, a pesar de su forma clásica, y és rico de subjetividad, a pesar de su objetividad aparente, superficial. Ese arte es trasunto fiel de su malogrado autor, hombre en quien de continuo se reveló una profunda dualidad:

el noble payanés, fiel a su raza española y su glorioso pasado, era hijo de América y vivía enamorado de su independencia;

y siendo de raza de azores, -fiero, enérgico, inflexible, tremante de aristocrático orgullo y de ansias invioladas de poderío y de imperio se sabía ser hijo de la Revolución americana, y sentía el amor del Nuevo Mundo y sus razas de color, y. anhelaba, como ellas, la justicia social que desciende, rutilante, de los brazos abiertos de la cruz!

En Arboleda se anidaba la soberbia patricia de su ciudad natal, -así llamaba él a Popayán, aunque no había nacido en ella- la embrujada ciudad de la cual pudo decir: 
..."Centinela tú fuiste del imperio y sus blasones; y en la abyección universal, tú sola quedaste libre, honrada y españo$l a " .$. Pero se anidaba también en él la voluntad americana de darle al continente adolorido y sangriento libertad, orden, ciencia, luz, igualdad, humanidad.

Leal a la hispanidad pura, eterna y universalista, y leal a su pasado medieval y renacentista, don Julio era un demócrata genuino, que aborrecía todas las tiranías del vicio, de la crueldad o de la fuerza. $Y$ siendo hombre de espada y caballero, amaba la palabra y reverenciaba la virtud y le rendía culto a la Ley. En su sentido más noble, podría decirse que era don Julio -así lo llamaron siempre, sus conciudadanosun verdadero cruzado en tierras de América, abiertas a todos los vientos del Espíritu. Y así es su Gonzalo de Oyón.

\section{$* * *$}

Se ha dicho ya que la gloria literaria de Arboleda estriba principalmente en su Gonzalo de Oyón, la gloriosa leyenda mutilada que, para nosotros, encarna un hondo simbolismo y tiene en estos momentos una actualidad verdaderamente inquietante.

"Siendo mùy joven, - según escribe don Miguel Antonio Caro- concibió Arboleda la idea de componer un poema - leyenda sobre algún argumento sacado de la conquista y colonización de América por los españoles; y registrando sus crónicas, se fijó en el episodio histórico de Alvaro de Oyón, que sobre ser de carácter americano, tenía para el novel poeta el encanto de estar conexionado con la ciudad de Popayán, cuna de sus mayores".

Esta noticia es interesante. Se ve que Arboleda,-que en Popayán de seguro había leído la bella prosa científicoromántica escrita por su muy ilustre pariente, don Francisco de Caldas (1770-1816) y también las poesías románticas de José María Gruesso (1779-1835), y que había estudiado en Londres- no recibió del argentino Echeverría,_-_"precursor del romanticismo en América" - ninguna influencia directa, y que por cuenta propia buscó en las crónicas payanesas el asunto para una leyenda líricodescriptiva... Y más intere- 
sante, para la historia del romanticismo, es que Arboleda recogiese (quizás de la Historia general de las conquistas del Nuevo Reino de Granada, de Fernández de Piedrahita, quien refundió en ella muchas crónicas antiguas), un episodio de escasísima importancia histórica, para infundirle ùn sentido trascendental y personalísimo: la rebelión de Alvaro de Oyón (1552).

La primera versión escrita que tenemos de dicha rebelión se halla en la "Elegía de Belalcázar", del candoroso y locuaz cura de Tunja don Joan de Castellanos, pero Arboleda no pudo sacarla de alli, pues bien sabido es que las famosas Elegías de varones ilustres de Indias - si bien escritas en el Siglo XVI- no fueron impresas sino años después de comenzar el payanés su poema.

Segứn Castellanos, era Alvaro de Oyón "arrojadizo, torpe, mentecato - Mas del mundo tenido comúnmente - Siendo hombre temerario, por valiente". Era natural de Huelva de España y nieto del comunero, don Pedro de Oyón. Envuelto en la rebelión que en el Perú encabezara Gonzalo Pizarro, y con él vencido, vino Alvaro de Oyón a Popayán, y de allí pasó a Santa $\mathrm{Fe}$ de Bogotá, donde lo conoció Castellanos, y pudo decir :

\footnotetext{
"Hombre más que mediano, bien fornido, $Y$ no de entendimiento delicado, Pues aunque fidalgo conocido, Bronco me pareció y avillanado. Andaba del demonio revestido, El rostro torvo, melancolizado"
}

De Santa Fe, don Alvaro volvió a Popayán, "revestido del demonio", y se dió a luchar por enseñorearse de aquella Gobernación, para luego marchar sobre Quito y extender si fuere posible su dominación hasta Lima. Reunió armas y compañeros, atacó varias poblaciones, y levantó pendón dándose el título de "Príncipe de la Libertad". En 1552 avanzó hasta amagar a Popayán y su plaza principal. La ciudad fué defendida por el Capitán Diego Delgado y el Obispo don Juan de Ovalle. Los rebeldes, en número de setenta y cinco, fueron derrotados y aniquilados: 
"Al Oyỏn y otros tres hicieron cuartos

Como culpados más en los excesos;

Cuelgan catorce de ásperos espartos

Sin gastarse papel en los procesos;

Manos y pico también cortaron hartos

De los que constó ser menos aviesos,

$\mathbf{Y}$ los otros, a penas más ligeras,

Azotes o prisiones, y a galeras".

Así habla Castellanos, y en eso... consistió la rebelión de Alvaro de Oyón, "Príncipe de la Libertad", nieto del comunero Pedro de Oyón, compañero de los Pizarros en la conquista del Perú, conspirador en Lima, en Quito, en Santa Fe de Bobotá y en Popayán, uno de los primeros españoles que en tierras americanas levantó pendón (jen 1552!) contra la tiranía de los reyes peninsulares... Poca cosa, sin duda alguna, fué el tal don Alvaro de Oyón, el "torvo", "melancolizado" y "avillanado" aventurero de quien nos habla Castellanos, y poca cosa sería su vida trágica y extravagante... Empero, un poeta que tenía ribetes de genio sacó de ella materiales suficientes para forjar una noble leyenda de recóndito y singularísimo sentido.

\section{$* * *$}

De joven comenzó Arboleda el Gonzalo de Oyón, pero sus manuscritos se perdieron en el aciago saqueo de que fué víctima su hacienda de Caloto, en 1851. Por fortuna, como él tenía para recordar sus versos "una memoria facilísima", en 1858 reconstruyó e hizo poner en limpio una parte de "su leyenda querida", y se la remitió a su amigo Lázaro María Pérez, - con una carta en la cual afirma que en su forma primera "tenía veinticuatro cantos", y que había gastado en escribirla "como diez años"-. Pérez publicó dicha parte en Bogotá.

Más tarde, en París, Arboleda revisó algunos cantos. Según dice Torres Caicedo, "en París vieron algunos fragmentos del Gonzalo de Oyón los señores Francisco Martínez de la Rosa y don José Zorrilla, y ambos literatos tributaron grandes elogios al autor", opinando que "la literatura espa- 
ñola al fin iba a tener un poema épico que merezca tal nombre"...

El poema no se publicó en París. Arboleda remitió los manuscritos a Colombia. Cayeron éstos en manos de sus ènemigos, y fueron destruídos! Lo que nos queda son los fragmentos publicados por Pérez, y lo que don Miguel Antonio Caro pudo salvar de algunos borradores que halló en manos de la familia Arboleda.

Dice don Miguel Antonio que Arboleda bosquejaba algunos cantos y episodios que iba luego modificando. "En los manuscritos que se han conservado se ven entrerrenglonaduras, enmiendas y apostillas sin cuento, estrofas truncas, lugares marcados como 'corrigenda', y lo que pone el colmo a la confusión, la numeración de los cantos varía y es contradictoria; unos mismos pasajes repetidos en diferentes partes, los más de los cantos inconclusos o fragmentarios, y trozos sueltos sin referencia alguna. Mezclados se reflejan en ese manuscrito en singular consorcio, el esfuerzo perseverante del poeta que venciendo dificultades lleva adelante su predilecto trabajo, y la irregularidad, el desorden a que están condenados hombres y cosas en medio de las agitaciones democráticas y de la anarquía crónica en que vivimos". Todos estos materiales los ordenó como pudo el señor Caro, dividiendo el poema en catorce cuadros - los tres últimos inéditos hasta entonces-, precedidos de un "Preludio", y bautizándolos con títulos bastante afortunados. La edición del señor Caro, publicada en forma definitiva en Nueva York, en 1884, es pues todo lo que queda de un poema que parece haber nacido bajo el signo de la tragedia en que vivió su nobilísimo autor.

***;

"El plan del Gonzalo-dice don Miguel Antonio-por la inexperiencia propia de los pocos años que contaba el poeta cuando lo trazó, adolece de grandes defectos, que ni el trabajo de la lima ni una refundición a medias hubiera sido parte a salvar"... "No hay allí una acción principal a que se refieran las empresas accesorias, y que avivándose a las veces, entreteniéndose otras en agradables episodios, progrese a la continua hasta llegar a su fin". 
Muchísima razón tiene el señor Caro. El poema carece de unidad y de acción propiamente dicha, y la poca que revela muy a menudo se ve interrumpida por largas descripciones de la naturaleza y por reflexiones de orden moral, político, religioso y teológico que la hacen confusa, vaga, casi imposible de seguir... $Y$ sin embargo, lo que sí se siente siempre en el Gonzalo es la personalidad de Arboleda y por lo mismo la trayectoria irregular de un gran pensamiento, la visión genial del destino mismo de la América hispana, como lo hemos de ver.

Arboleda no se ciñó a las crónicas coloniales relacionadas con la rebelión de Alvaro de Oyón. Con libertad de romántico, él creó personajes, $\mathrm{y}$ episodios, y les dió a unos $\mathrm{y}$ a otros un inquietante valor simbólico cuyo sentido -que nosotros sepamos- nadie todavía ha querido explicar, quizás por hallarse envuelto en velos de misterio, o porque la historia todavía no se ha desenvuelto suficientemente para revelarlo en todo su rigor. Nosotros vamos a intentar aquí una interpretación del Gonzalo de Oyón.

Siguiendo, cuadro por cuadro y verso por verso, el desarrollo de la leyenda, podríamos decir que su argumento es, o fué, quizás, así :

Gonzalo de Oyón, hijo de don Gaspar de Oyón, y nieto del comunero de Huelva, don Pedro, viene de España con los conquistadores. Después de haber ejecutado varias proezas en la campaña de Pasto - región del sur de-Colombia habitada por tribus de indios muy aguerridos e independientes-, llega a Popayán, ciudad poco antes fundada por don Sebastián de Belalcázar (que también llaman algunos Benalcázar). Allí don Gonzalo intercede por el Cacique Pubén, 'que iba a ser sacrificado por los españoles, y le salva la vida. Ocurre, empero, que Fernando Belalcázar, hijo del fundador, pone atrevidos ojos en Pubenza, enamorada de don Gonzalo e hija del Cacique. Fernando condena a Pubén y a uno de sus hijos a muerte, y la infeliz india, a trueque de redimir a su anciano padre, se resigna a casarse con Fernando, sin amor, pues es novia de don Gonzalo. Don Fernando, celoso y vengativo, calumnia y destierra a su rival, y éste se retira a vivir vida de ermitaño en los bosques. 
Pocos años después, desterrado por rebelde del Perú don Alvaro de Oyón, hermano de don Gonzalo, vuelve armas contra la autoridad del rey de las Españas, y asistido por su cómplice, el pirata Walter, busca auxiliares entre las tribus indígenas que quieren sacudir el yugo español, reúne un ejército y marcha sobre Popayán. Gonzalo, que pasaba por muerto, aparécese de pronto en medio del combate, y lo decide en favor de la causa del rey. Fernando lo reconoce, y obedeciendo a una inspiración diabólica, lo declara fuera de la ley, lo tacha de traidor y ponie a talla su cabeza. Pubenza, que no se ha olvidado de su Gonzalo, le escribe una carta pintándole el peligro que lo amenaza, y rogándole que se ponga en cobro. Gonzalo se ausenta y busca abrigo entre las tribus salvajes. Propónenle los indios' que tome el partido de ellos contra los españoles; él se niega a hacer traición a su raza; intentan matarle, huye él, y se hospeda en la guarida de Caleb, misterioso ermitaño de las montañas de Toribío.

Entre tanto, don Alvaro rehace sus huestes y torna a amagar a Popayán. Otro batalla: preséntase Gonzalo de nuevo como en la primera, $y$ lo mismo que entonces decídela en favor del pendón real. Ocúltase Gonzalo, pero a campo raso y en lá oscuridad de la noche, se encuentra con su hermano Alvaro, sin reconocerlo. Luchan gallardamente los dos hermanos. Vence Gonzalo, y al reconocerse, cada uno alega las razones que le asisten para seguir adelante: Gonzalo, en defensa de la causa real, y Alvaro en su contra.

Hay una tregua. Gonzalo se ve con la india Pubenza. Sorpréndẹlos Fernando, se vuelve loco, huye y mata a sus tiernos hijos, y sólo en sueños lo ve Gonzalo.

Los partidarios del rey español les ofrecen perdón y olvido a los sublevados que acaudilla don Alvaro: Rehusa éste la gracia, y dispersa a los indios que lo siguen y que, al despedirse, le ofrecen regalos de oro que él de un puntapié echa a rodar al suelo. Amotínanse contra él los indios gritando: "¡Traición!”. Don Alvaro ahorca a los principales, y concluída la tregua, y vencido por las lágrimas de su madre, María, levanta el-sitio de Popayán y desaparece para siempre.

En este argumento vemos ya las fuerzas opuestas que 
luchan entre sí sin que ninguna de ellas logre el triunfo definitivo. En su desarrollo, veremos mucho más.

"En Arboleda-dice Menéndez y Pelayo-se ve intención deliberada de envolver en su sencilla fábula"... "un pensamiento mucho más alto, una especie de filosofía de la conquista española en sus relaciones con las razas bárbaras y con el futuro destino de las sociedades americanas".

Ya había escrito antes el señor Caro: Arboleda confronta a los dos hermanos de Oyón, y su lucha es "controversia... de valor altísimo, porque refiriéndose ocasionalmente a un episodio fantástico, tiene aplicación natural a la pugna perpetua que ha sostenido y que sostiene en nuestra América española el patriotismo genuino y anchuroso que respeta las tradiciones y ama la unidad nacional, contra esas ambiciones bastardas que, proclamando la libertad, sólo aciertan a dividir las voluntades concordes, y a demoler la existencia".

De veras, en el Gonzalo de Oyón, Arboleda, apoderándose de un episodio insignificante de la conquista de América por los españoles, construye una "fábula", en parte "fantástica", y se levanta a grandes alturas, haciendo intervenir personajes alegóricos, - la Fe, la Religión y otros-en las relaciones entre los personajes históricos, -Alvaro de Oyón y Fernando de Belalcázar-y los que son pura creación del poeta, - Gonzalo de Oyón, su madre María, la india Pubenza, el pirata Walter y otros. El poema está cargado de simbolismo, en la caracterización de los personajes históricos y legendarios, en las situaciones, $y$, por encima de todo, en la intervención romántica del poeta, quien a menudo se proyecta en la acción dramática y la interrumpe por medio de reflexiones y discursos lírico-apologéticos acerca del ideal religióso que encarnó la España aventurera e imperial del Siglo XVI y que, en estos momentos, adquiere nueva beligerancia no sólo en la Península sino en América.

Desde luego, en el poema los dos personajes centrales son Gonzalo y Alvaro de Oyón. Vienen en seguida Pubenza, Fernando, el pirata Walter, María y otros. Sin duda alguna, todos son personajes simbólicos que encarnan las ideas éticas, sociales, políticas y económicas - y las fuerzas y hechos 
a ellas concomitantes-que el poeta ve en juego dramático disputarse entre sí el predominio de América.

Gonzalo de Oyón, -en quien Arboleda quiso retratarse a sí mismo sin lograrlo- es en el poema el caballero sin tacha, leal a su dama y a su patria española. Es un joven idealista, valiente, quijotesco, que desciende de una raza "clara en bélicas hazañas" y que "sigue la paterna huella" porque "en esos tiempos la virtud guerrera - temprana herencia de los hijos era". Es el soldado de la España imperial, fiel y piadoso, que "lidia de honor sediento", a quien "la hueste ibera" sigue con entusiasmo por ser tán grandes "su prudencia y su virtud". Es el consejero, el héroe invicto, "idolo de las huestes vencedoras", "amparo del infeliz americano", "alma gentil" que sólo anhela el bien de todos y que para todos lucha, "ora modesto, intrépido a su vez". Es el cruzado de la cau-" sa...

"Flor solitaria en espantoso yermo,
Que Dios puso entre espinas y entre abrojos
Por dar alivio a los cansados ojos
Heridos del calor del arenal!
¿Unica fuente en árido desierto
Que refresca al sediento peregrino!
iSola enseña de bien en el camino
Por donde siembra la conquista el mal!"

En cambio, su hermano Alvaro de Oyón, compañero de Pizarro y "en valor su rival, mejor guerrero", varón "con voluntad de hierro", "activo, emprendedor", es un ambicioso, "sin ideales":

"Don Alvaro de Huelva, belicoso Hijo de España, y su enemigo crudo:

Don Alvaro, rebelde $y$ orgulloso

Nieto de Oyón el comunero rudo, Don Alvaro, enemigo del reposo, En cuyo pecho empedernido, mudo, Arde perenne de ambición la tea, $Y$ en la sangre $y$ la muerte se recrea. Su amor la guerra, el pabellón del cielo Su mejor techo; el césped esmaltado Su lujoso sillón; su lecho el suelo, 
Y su festín el campo ensangrentado;

Su deleite las armas, el desvelo,

El peligro afanoso $\mathrm{y}$ angustiado:

Avida sed de imperio y de renombre;

Su mundo él, y su juguete el hombre".

Don Alvaro de Oyón, "rebelde, y de rebeldes hijo y nieto", es un espíritu egoísta para quien "es tráfico su fe" y la conducta su propia "conveniencia"; es un espíritu diabólico, cuyo "ánimo guerrero" no reprime "el santo temor de Dios", y para quien "fué su dios la Venganza, y su derecho"; es un temible individualista, dè "raza noble y altanera", que "jamás a la ley tuvo respeto" y para quien es "la autoridad quimera, lentejuela de teatro, cuyo precio ignora el débil y deslumbra al necio": es un hombre "denodado y fuerte" cuyos blasones son la audacia y el valor, el desprecio de la muerte y de la suerte. Es un aventurero que persigue "con esfuerzo y esperanza un objeto tan sólo - la venganza".

$\mathrm{Y}$ sin embargo, siendo hermano de Gonzalo, hijo y nieto de comuneros de Huelva,
"Sólo una alta virtud su seno abriga
Inextinguible, como el puro fūego
Que conserva la vestal antigua;
$Y$ arde su llama en plácido sosiego,
Sin que del mundo injusto la enemiga,
$\mathrm{Ni}$ el furor de ambición violento $\mathrm{y}$ ciego,
Su luz apaguen. A sus padres ama
Aun más que trono, y. vida, y dicha, y fama".

Como vemos, Arboleda establece un contraste extremoso entre los dos hermanos de Oyón: angélico el uno,-el otro diabólico... Y Y no obstante, los dos son hermanos y españoles, $\mathrm{y}$ por lo mismo tienen un mismo e idéntico origen, $\mathrm{y}$ un mismo destino. ¿No tendremos el derecho de decir que don Gonzalo y don Alvaro son el desdoblamiento - poetizado- del alma española y su proyección en la América? La situación antagónica en que Arboleda los coloca en su poema - de la cual hablaremos algo más-, y el hecho de unirlos en el amor de sus padres, así parece indicarlo. 
Vimos antes que Luis Alberto Sánchez - a quien tanto preocupa el indigenismo- sostiene que Arboleda trató el te$m a$, y que lo hizo "en el sentido descriptivo y externo en que lo cultivó Echeverría". No lo creemos nosotros. Al contrario, diremoś que el poeta de Popayán no sólo comprendió el problema indígena, sino que lo sintió en toda su punzante realidad histórica y vital, y que de él hizo uso en su Gonzalo de Oyón, idealizándolo y dándole por lo mismo una noble y alta proyección. En efecto, en el poema la raza indígena - ternura, pureza, mansedumbre, belleza moral, esteticismo hondo y noblemente espiritualizado-se halla hecha carne en la figura simbólica de la india Pubenza, hija, nieta y biznieta de caciques indios del hermoso Valle de Pubén, asiento de la patricia ciudad de Popayán. En el poema, Pubenza es nada menos que la amada del angélico caballero don Gonzalo, encarnación él del más puro y genuino y noble españolismo quijotesco. Arboleda busca inspiración en las baladas germanas, y colores en el petrarquismo renacentista para pintarnos a la india Pubenza:

"Dulce como la parda cervatilla, Que el cuello tiende entre el nativo helecho, $Y$, a la vista del can, yace en acecho, Con sus ojos de púdico temor:

Pura como la cándida paloma Que de la fuente límpida al murmullo, Oye, al beber, el inocente arrullo, Primer anuncio de ignorado amor;

Bella como la rosa, que temprana, Al despuntar benigna primavera, Modesta ostenta, virginal, primera, $\mathrm{Su}$ belleza en el campo, sin rival; Tierna como la tórtola amorosa, Que arrulla viuda, y de su bien perdido

La dura ausencia en solitario nido Llora, y lamenta su incurable mal;

Brillante como el sol, cuando refleja Sus rayos el cristal de la montaña, Si ni la lluvia, ni la lluvia empaña Su naciente, purísimo esplendor: Majestuosa cual palma, que se eleva, 
$Y$ ostenta en la vastisima llanura

Su corona imperial y su hermosura, Desafiando el rayo del Señor".

$\mathrm{Y}$ sigue la "descripción" (?) de la indiá en cuya "frente pálida vagaban el dolor y la negra pesadumbre"; "india en amar, en resistir cristiana", "malhadada" princesa en quien "todo respira amor, pureza, hermosura"; mujer de alta y noble virtud sobre quien pesa "el yugo de despótico señor", ya que, siendo la enamorada de don Gonzalo, tuvo que sacrificarse a sí misma y casarse con don Fernando Belalcázar para salvar así la vida de su padre; el indio Pubén.

¿Y quién es este don Fernando, y qué pasiones lo mueven? Oigamos al poeta:

"Fernando Belalcázar, el soberbio, Ama a Pubenza, adórala; alimenta Su alma altanera, inđómita, violenta, La inextinguible, la feroz pasión: $Y$ de todo es capaz: un pensamiento Ocupa entera su existencia amarga, $Y$ del funesto amor bajo la carga, Se agita su rebelde corazón.

$Y$ poderoso, del poder abusa;

$\mathrm{Y}$ celoso, corteja la venganza;

$Y$ furioso de amor sin esperanza, Busca en el crimen su único sostén;

Su carácter de fuego no permite Contradicción ni leve resistencia, $Y$ en su absurda despótica potencia Busca el camino de un soñado Edén.

Cetro de hierro empuña; vida y honra, Todo está a su capricho encadenado:

En el imperio vasto conquistado No hay más que su firme voluntad; Ella manda, ella impera, ella se cumple, $\mathrm{Ni}$ hay donde huír del lúgubre tirano; Que se siente doquier su férrea mano Cual vasta, universal calamidad". 
Don Fernando es la encarnación del conquistador de América, del déspota violento que, movido por la pasión, y haciendo uso de la amenaza y de la fuerza, llegó, - - en el poema-a maridarse con la dulce Pubenza, encarnación ella de la ternura y la pureza indígenas, así como tantos de su clase, -en la historia-se maridaron también y echaron en el vientre de las indias la simiente de una pasión que no era el amor!...

Cierto es que el "romance" de don Gonzalo y de Pubenza no llega en el poema a desenvolverse plenamente, y que allí aparece, platónico y tímido, y medio oculto en velos de misterio, bien porque el poema nos quedó mutilado, bien porque así convenía a la manera románticã que Arboleda amaba, a pesar de su "clasicismo" tradicionalista...

$Y$ aquí es bueno hacer una consideración de enorme interés:

En el poema, Gonzalo, "amparo" de los indios americanos, caballero ideal, no lucha contra el despotismo legalista $y$ violento de don Fernando, ni contra sus injusticias; no lucha contra el rival que le roba a su amada Pubenza, y que sin motivo legitimo lo pone fuera de la sociedad, y lo calumnia llamándole "traidor", y lo persigue y pone a precio su cabeza... ¡No! Gonzalo no lucha, como debe, sino que se retira a vivir en las selvas - penitente sin pecados que expiar-, solo, humillado, escarnecido!... Y quien sí lucha contra el tirano a quien ampara la santidad de la "ley", es el "rebelde" y vengativo don Alvaro!... Detengámonos un poco en este punto, de tan singular sentido histórico y vital para nuestra América.

Arboleda, - español de sangre y por tradición, americano de nacimiento y en esperanzas-quiso que su héroe Gonzalo fuese el tipo ideal del caballero leal a su Rey, a su Patria y a su Dama, y que su antihéroe Alvaro fuese la encarnación de las "ambiciones bastardas" de que en su comentario nos habla don Miguel Antonio Caro. Pues bien: Quizá inconscientemente, Arboleda le dió a don Alvaro mayor grandeza y energía que a don Gonzalo. La paradoja es brillante: Nos parece que el poeta, con todo y a pesar de todo, se sentía más americano que español! 
Veamos qué hace don Alvaro en el poema, $\mathrm{y}$ oigamos de sus propios labios las razones que lo mueven a levantar pendón contra el Rey de las Españas.

En primer lugar, don Alvaro busca una doble alianza, con los indios, por una parte, y por otra, con el inquietante pirata bretón Walter, "hombre en apariencia misionero"..., "raro peregrino" cuyo destino es "anarquizar el mundo", que les sirve a los rebeldes "en odio a España", y que, siendo "diestro en el mal, y para el mal nacido", ha venido a la América española con miras ocultas y siniestras.

Aliados don Alvaro y Walter contra el Rey de las Españas, tienen un proyecto de épica grandeza: la conquista, para ellos y para la libertad, de toda la América!

Solos, en la selva, don Alvaro y Walter contemplan el mapa del continente americano, con sus montañas riquísimas en maderas de construcción y en metales preciosos y útiles, y sus ríos de enorme caudal y sus inmensos lagos; propios todos para la navegación, y sus mares, que lo comunican con el resto del mundo... $Y$ se exaltan los dos, $y$ hacen votos de dominar a la América entera, y de construir en ella, no sólo grandes caminos que la crucen en todas direcciones, sino canales que comuniquen sus mares. Así habla don Alvaro:

\footnotetext{
"Ya de Colón el genio sin segundo, De una idea profético inspirado, $\mathbf{Y}$ de su audacia $\mathbf{y}$ su saber llevado, Buscó un estrecho para unir el mundo, Que paso entre los trópicos le diera $Y$ en uno los dos mares confundiera. No existe, nó; pero en la tierra adentro, No lejos del escudo de Veragua, Manso se extiende el lago Nicaragua Del istmo estrecho carcomiendo el centro, $Y$ arroja un río sobre el mar de Oriente, $\mathbf{Y}$ enlázase al Managua hacia el Poniente. Que nos sirva el Atrato, o ese lago, $\mathrm{Si}$ al fin nuestro dominio establecemos, Justo será que el sueño realicemos De tanta dicha $y$ de poder presagio. $Y$ que de Asia y de Europa el rico fruto Pase, y pague al pasar, pingüe tributo".
} 
Don Alvaro aspira a construir grandes astilleros en varios lugares de la costa del Pacífico, y quiere tener una armada, más que un ejército. Se siente atraído por el mar, que anhela someter a su señ்orío:
"Dueño del mar, de aquella ruta vasta, Que al impulso recórrese del viento, Deberé mi poder al movimiento. Un puñado de fieles: eso basta; Ese puñado, con honor, doquiera Tremolará, triunfando, mi bandera. Brazos me sobrarán. Ya con decoro Al Italiano, al Portugués invito, Y la nativa emulación excito Con regia pompa, y con honores y oro, Que así la ciencia me enviará su tropa, Que los reyes desprecian en Europa".

Realista, ambicioso, imaginativo, heroico es en verdad don Alvaro... Nada tiene que envidiarles a los grandes conquistadores del mundo, cuya técnica y cuya diplomacia conoce $\tan$ bien!

Sigue el "rebelde" hablando en detalle de las posibilidades y potencialidades de la América que quiere dominar, y exclama:

“ $\mathrm{O}$ Oh! parece que el Ande me adivina $\mathbf{Y}$ ante mi voluntad el lomo inclina!"

"Todo es propicio aquí: las ensenadas, Las islas protectoras y bahías, Los esteros innúmeros, las rías, Brindan seguro asilo a las armadas, Que esperan de las selvas su sustento, $\mathrm{Y}$ su fácil y rápido incremento".

¡El mar!... ¡El mar!... Porque

"Poderoso auxiliar en su corriente Tendrán el estadista $y$ el soldado; Porque este mundo, Walter, le domina El primero que tenga una marina". 
"El que domine el piélago profundo, $\mathrm{Y}$ en su furor se extasie $\mathrm{y}$ se divierta; El que poblando su extensión desierta, Se adueñe de ese vínculo del mundo, Ese, por las tormentas arrullado, Tendrá en su diestra al mundo encadenado. $Y$ no será europeo, que sus reyes Son muchos, fuertes son sus disensiones;

Se espian, se aborrecen las naciones;

Tienen distintos usos, varias leyes, $Y$ la unidad de acción $\Psi$ pensamiento Es base del poder y su elemento".

"Alega el rey de España sus derechos $A$ este nuevo y magnífico hemisferio! ¿Qúe derecho tiene él sobre un imperio Que han conquistado nuestros altos hechos? Colón le halló, y a su hijo el grande hombre Ś́lo legó sus grillos y su nombre".

"Al fin aquel intrépido marino, Pesar sintiendo en su cerebro el mundo, Se abrió por entre el piélago profundo A su creación fantástica el camino; La halló; y mi padre, de Colón amigo, Le vió morir la muerte del mendigo! Sin embargo, mi padre generoso Volvió a verter su sangre en esta tierra: Por el Rey, para el Rey hizo la guerra: Sacrificó familia, hogar, reposo, Todo para ser muerto oscuramente, iAy! y dejar la infamia en nuestra frente. Sus canas, sus servicios, no pudieron Redimir el honor del buen anciano. ¡Así nos paga el Español tirano!"

Como se ve claramente, don Alvaro-antihéroe del poema-, no se rebela contra su patria, ni contra su raza (ya vimos que "a sus padres ama aun más que trono, y vida, y dicha, y fama"), sino contra la ingratitud del Rey, contra su injusticia, manifiestas las dos no sólo en lo que hizo contra el Descubridor de América, sino contra quienes (como el pa- 
dre mismo de don Alvaro y de don Gonzalo de Oyón) habían sacrificado "familia, hogar, reposo", en tierras de América. Don Alvaro, en su "rebeidía", se niega a reconocer el derecho que el Rey reclama para sí de dominar las tierras que el pueblo español ha conquistado con sus "altos hechos" de valor, de audacia, de abnegación, de resistencia y de perseverancia inauditas en la historia:

Esta actitud de don Alvaro se realza más en otra parte del poema. Al encuentro en que, a campo raso, en la oscuridad y de espada a espada luchan sin reconocerse al principio los dos hermanos de Oyón, y en el cual quedó herido y vencido, temporalmente, don Alvaro, sigue una disputa verbal entre los dos. Don Alvaro le explica a su hermano por qué ha levantado pendón contra el Rey de las Españas, por qué arde en ansias irresistibles de venganza: porque el Rey traicionó a Colón, y porque el Rey persiguió a los españoles que en Colón veían a un gran benefactor de España y de su raza, y entre aquéllos a don Gaspar de Oyón, que tan noble y gallardamente había luchado en América por el Rey. Y porque, allá en la Península,
"Veintitrés hidalgos (ioh, qué hidalgos!)
Dijeron bajo santo juramento
Que de esta tierra espléndida el invento
No era obra del piloto genovés"...

y porque

"Oh vergtienza! esos actos oprobiosos
De ingratitud flagrante y cobardía
Los inspiraba el Rey; los protegía
Con una vil y sórdida intención"...

y porque don Gaspar de Oyón, hombre "sencillo, generoso, abierto", compañero de los Pizarros en la conquista del Ṕerú, de Quito y luego de Benalcázar, en la conquista de Popayán, había caído, calumniado y deshonrado por "esos malvados" que "con el foro y la ley sólo especulan", y había sido condenado a muerte y confiscadas sus propiedades "en nombre del Señor de España", y por "el asesino" que en Popayán 
vivía, imperaba, castigaba y robaba sin piedad!... Don 'Alvaro, pues, lucha contra la "justicia" que se hace en nombre del Rey, y porque quiere hacérsela con sus propias manos de guerrero independiente. Así exclama:

\footnotetext{
"Yo soy hijo y soy súbdito; un delito

Me privó de mi padre, y fué maldito

El pueblo que lo quiso consentir.

Verdugos fueron jueces $\mathrm{y}$ testigos;

Mas cuantos el delito permitieron

A par de los verdugos delinquieron,

$\mathrm{Y}$ deben por sus crímenes morir!"
}

"La autoridad, cuando en su nombre imperan

La envidia vil y la cobarde intriga

Es un mal, no es un bien; es la enemiga

Del hombre, y él la debe derrocar.

Contra los fuertes se inventó el Gobierno

Para dar protección al desvalido

Contra el malvado aleve y atrevido,

Para dejar al bueno descansar.

¿Mas quién se atreve a sostener que el hombre

Renunciase a su dulce independencia

Para entregar la cándida inocencia

Al perjuro, al falsario, al impostor?

Más vale la elevada tiranía

Que ejercen los valientes con la espada,

Que esta coyunda vil que nos degrada

Haciendo al más cobarde el opresor".

$\mathrm{Y}$ en seguida, en un arranque democrático, revolucionario y americano, don Alvaro invita a su hermano a que lo siga en su lucha contra el Rey y sus Tenientes, contra la "informe" y "gastada" máquina de la monarquía, que deben destruir, y "otra nueva" alzar "sobre cimientos sólidos", en el "mundo virgen" americano, donde conviene elevar un "monumento a la filial piedad", y erigir "un trono a la justicia". $\mathrm{Y}$ es elocuente, animoso, inflexible: " $\mathrm{i}$ Vén!"-le dice:

..."los jueces no lidian. Esas hienas

Togadas, sólo con la pluma tratan:

Cuando ellos nos deshonran y nos matan, 
Es porque está a cubierto su maldad.

Los jueces son invulnerables. Ellos

No tienen quien los hiera ni los veje:

Si el malo los corrompe y los protege,

Los tolera la imbécil sociedad".

"Vén, venn hermano! La virtud vencida,

Mísera y pobre por la tierra vaga,

Mientras el mundo en su abyección halaga,

Premia y corona al crimen vencedor".

Las razones de don Alvaro-que serían las de tantos otros soldados y colonos del pueblo a quienes aniquilaron mil veces los togados y burócratas que con el Rey de las Españas administraban sus posesiones de América, que aquéllos regaban con su sangre- no convencen a don Gonzalo el héroe quijotesco del poema... Al contrario: don Gonzalo sigue siendo leal al Rey, en cuyo nombre lo persiguen; a su dama ( $\mathrm{Pu}$ benza) y a quien un Teniente del Rey maltrata y humilla; a su patria lejana... que gime dolorida entre las garras de una burocracia que se precia de hidalga y valiente, y sólo es togada, envidiosa, cobarde e injusta.

¿ $\mathrm{Y}$ qué razones alega a su turno don Gonzalo para explicar su lealtad conmovedora, patética y sublime? Varias, que pueden sintetizarse en una palabra: ¡Dios!

No cree don Gonzalo que puede ser "justa" la rebelión de su hermano por más que se vea éste perseguido por la llamada justicia del Rey y su representante en Popayán. Porque don Alvaro "no tiene derecho" para hacer causa contra el Rey, en compañía de un pirata inglés enemigo de los españoles, y en la de una "turba de sacrílegos bandidos que al resplandor de la incendiaria tea, en salvaje algazara se recrea con esa sangre en que embriagada va..." Gonzalo no puede. ni siquiera imaginar que con esos elementos podrá su hermano vengar la muerte de su padre:

....."Con traidores

No se lava el honor amancillado,

Ni se reforma el hombre. Tú inmolado

Serás de esos malvados al furor." 
Así arguye, magníficamente, el caballero. $\mathrm{Y}$ continúa:

"¡No! Jamás el delito regenera;

Que está en el cielo y en la tierra escrito

‘Ay! que el delito engendrará delito,

La infamia infamia, la traición traición!

$Y$ aunque logres vencernos, nunca, hermano,

Conocerás la paz ni la ventura:

Dolor interminable, honda amargura

Tus hechos y doctrinas brotarán.

Los que a vencer por interés te ayuden

También por interés te harán la guerra,

$\mathbf{Y}$ aspirando al dominio de la tierra,

Como calculas tú calcularán.

$\mathbf{Y}$ se equivocarán, cual se equivoca

El hombre siempre, en su opinión falible;

$\mathrm{Y}$ en desorden satánico $\mathrm{y}$ horrible,

La ambición empujando a la ambición,

A la envidia la envidia, el lucro al lucro,

Y el egoísmo torpe al egoísmo,

La sociedad sin fe, sin patriotismo,

Hervirá en loca, eterna confusión.

En caos espantoso, donde el crimen

Con que pretendes dominar el mundo,

Será tan sólo en crímenes fecundo,

Tanto que de tus obras temblatás,

$Y$ en lugar de juntarse, separados

Los pueblos por la fuerza del delito,

Cada cual contra ti lanzará el grito

Que con tu ejemplo autorizado habrás".

....." No pienses que a la lumbre

De sacrílega espada parricida

Cobre vigor la sociedad herida;

Al vicio le corrige la virtud:

La virtud, que redime y no esclaviza". 

testa:

$\mathrm{Y}$ como don Alvaro le pregunta: ¿qué es virtud?, con-

-"El sacrificio

Del yo por los demás: el santo olvido

Que hace del hombre calumniado, herido,

Un héroe en el amor $\mathrm{y}$ en el perdón",

para ganar así

........................"la dicha

De todas las naciones, que se extiende

Como el ejemplo se propaga, y prende

El bien de corazón en corazón...

Eso es virtud: el interés no dicta

iSér mártir y hacer bien! Tal es la santa

Ley del linaje humano redentora:

Imitar la paciencia bienhechora

Del que bajó a morir por la verdad,

De su alto ministerio el ejercicio;

Ella se da a sí misma en sacrificio

$Y$ muere por salvar la humanidad".

Don Alvaro quiere saber quién premia el dolor de los leales que sufren y luchan como su hermano, y éste responde: ¡Dios!

............ La humanidad se postra

A adorar el poder, no la virtud!

Sé que al brillo del oro, $\mathrm{y}$ al reflejo

De la grandeza, múdanse los hombres

$\mathrm{Y}$ a los delitos dan brillantes nombres

Que engañan a la imbécil multitud.

Porque todo es mentira acá en la tierra:

Nos miente la criatura a quien amamos,

Miéntennos los objetos que miramos,

Nos miente y nos engaña el corazón.

Miéntenos la esperanza que nos guía,

Nos miente la lisonja y nos acecha,

Miéntenos la venganza, aun satisfecha,

Nos miente, aun victoriosa, la ambición". 


\section{"El poder no es justicia, aunque los hombres Al vencedor adulen"...}

Empero, las sublimes razones - quijotescas-de Gonzalo no convencen a don Alvaro, de la misma manera que las de éste - tan realistas- no convencen a aquél: los dos hermanos viven en mundos diferentes y tienen dialécticas opuestas, idealista la una, la otra materialista, y su conflicto es eterno. $\mathrm{Y}$ sin embargo, al seguir debatiendo la cuestión, don Gonzalo menciona a su madre María, y el filial recuerdo conmueve profundamente a su hermano, tan profundamente, que se suspende el debate, y continúa la acción del poema, con sus batallas, sus visiones, etc., para llegar a su "final" (?), en una escena de hondísima ternura: el "satánico" don Alvaro se retira definitivamente del campo al ver que Maria llora por la suerte de los dos hermanos...

Sin duda alguna; María es, como los otros, un personaje simbólico que tiene el poder de hermanar las fuerzas opuestas que encarnan en don Gonzalo y don Alvaro, identificándolas en su origen y su destino, y dándoles virtualidad creadora aun en medio del conflicto. ¿Será este personaje el símbolo de la hispanidad misma, o tendrá relación con el culto mariano que persigue en su trayectoria histórica?

A España y a la América les corresponde contestar esta pregunta.

"Si se atiende a su acción - dice Menénđez y Pelayo, siguiendo en ésta como en otras opiniones' a don Miguel Antonio Caro-, obscura en la historia y de interés muy secundario en la conquista de América, el Gonzalo de Oyón más bien merece el título de leyenda o de novela en verso, como algunas de Walter Scott, que el de poema épico en el sentido clásico", $\dot{y}$ "aunque en algunas cosas se aparta del tipo de los poemas italianos, en muchas otras los recuerda, y para leyenda resulta demasiado largo y solemne".

Considerando pues las rígidas categorías de la preceptiva, el Gonzalo de Oyón no es novela, ni leyenda, ni poema épi- 
co... ¿Qué será esta mutilada obra, cuyo sentido quisiéramos conocer a ciencia cierta?

En el Gonzalo de Oyón usó el poeta de varios metros y formas estróficas. En la narración impera la octava rima en dos distintas formas: una, la clásica y tradicional, la octava italiana de Ariosto y del Tasso, "que Arboleda maneja con singular gallardía", y otra romántica, compuesta de dos cuartetas, sin más enlace que el de los finales agudos: es la octava que hemos llamado bermudina en América, por haberla usado con mucha gala y muy a menudo el poeta español don Salvador Bermúdez de Castro, que no fué su inventor: es una estrofa lírica de "engañosa facilidad" y muy propensa al amaneramiento, y que, "si algún ejemplo pudiera redimirla, sería ciertamente el del Gonzalo de Oyón". En otras partes del poema, Arboleda usó de sextinas, y aun de cuartetas en esdrújulos, que amaron los románticos de aquende' y allende el mar...

El poeta fué libre en la escogencia de la materia.del poema, los personajes, las situaciones, $y$ las formas métricas. $Y$ fué más lejos:

Si en ocasiones se esmera en la pintura animada, dramática, fiel y seductora de algunos incidentes, o en la colorida $y$ leal de la naturaleza ambiente, no se niega a hacer que en la acción dramática tomen parte figuras alegóricas y sobrenaturales, ni titubea al echar mano de toda clase de elementos, visiones fantásticas, apariciones, y demás del arsenal romántico, porque

\footnotetext{
"Si las vagas visiones de la mente Nos parecen ensueños y quimeras," Esas sombras errantes, pasajeras, Forman parte también de la Creación".
}

Y como la tragedia se cierne sobre todos los personajes y situaciones del Gonzalo de Oyón, resulta éste algo menos que epopeya ... un drama descriptivo, lírico y épico, algo en parte semejante a los dramas griegos donde la sombra de un destino inexorable revuela en torno de los héroes y las cosas. Contiene el Gonzalo de Oyón muchos versos débiles, fràses prosaicas, pasajes incorrectos, y reflexiones que a veces $5 \star$ 
pecan de vaga y vana palabrería... Pero contiene también mil rasgos de feliz ingenio y brillante imaginación; dicción pura, fácil; versos melodiosos, y sentencias expresivas, metálicas, penetrantes... Y principalmente, muy notables descripciones, entre las cuales se distinguen y han logrado mucha fama la del caballo y la del duelo - espada a espadaque tienen don Alvaro y don Gonzalo, $\tan$ valiente, vigorosa, vívida e impresionante. Arboleda, como dice Isaac J. Barrera, al expresar en su poema "la inquietud vivaz de su espiritu", logró crear "ciertos rasgos esenciales de un romanticismo que influyó notablemente en su patria y en buena parte de América".

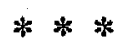

Mucha razón tuvieron Caro y Menéndez y Pelayo al afirmar que el Gonzalo de Oyón es "el más notable ensayo de la poesía americana en la narración épica", y ninguna tuvo Cejador y Frauca para no aceptar esa afirmación que limita y. clasifica la obra de Arboleda, sin quitarles valor a otras, tales como el Tabaré y La cautiva, que son de índole diversa, como todos lo sabemos, y que en realidad no pueden llamarse "narraciones épicas".

Al emitir su opinión, Caro y Menéndez y Pelayo, apàrentemente, pasaron por alto La Araucana, de Ercilla, sin duda por considerarla obra de "ingenio español", que no americano, y pasaron por alto el Martín Fierro-que ellos admiraban muy sinceramente-quizás porque el poema argentino no es precisamente una "narración" y porque, siendo esencialmente popular, no sigue las normas "clásicas" de las epopeyas modernas a la italiana.

Mas no se crea que Caro y Menéndez y Pelayo le daban más importancia, como poema épico, al Gonzalo de Oyón que a La Araucána, obra para ellos española, a pesar de estar henchida de cierta inconsciente americanidad que brota, no sólo de las descripciones de la naturaleza chilena - no muy sentida por Ercilla-, sino que también de la caracterización de los indios araucanos a quienes el conquistador poeta supo de veras respetar por la virtud, la dignidad, la fiereza y el "pa- 
triotismo" con que lucharon. Lo que hay es que, por razones de conveniencia, tanto Caro como su amigo Menéndez y $\mathrm{Pe}$ layo' a menudo llaman "español" a todo autor anterior a la guerra de la independencia y nacido en la Península o en América, y llaman "americano" a todo autor nacido en América después de dicha guerra "civil", sin cuidarse de si eran argentinos, colombianos o mexicanos... Para el amplio y noble patriotismo de los dos príncipes de la crítica española, lo "español", antes del Siglo XIX, era tanto lo de allende como lo de aquende el mar, y después, lo "americano" era todo lo comprendido entre California y el Estrecho de Magallanes.

Razón tuvieron Caro y Menéndez y Pelayo al considerar el Gonzalo de Oyón superior, como "narración épica", al Tabaré de Zorrilla de San Martín y a La cautiva de Echeverría.

Tabaré (1888) parece "bella serie de poesías líricas, en las cuales la acción se va desenvolviendo" en un ambiente admirablemente sentido por el autor, como nos lo dice don Juan Valera. Envuelta en velos misteriosos - de origen becqueriano-, aparece allí la figura del mestizo Tabaré y "queda siempre en esfumada indeterminación lírica"... Y aùque 1 el final del poema es trágico y sombrío y está escrito en versos de "un brío gráfico y fantástico", no deja aquél de ser más lírico que épico, y más descriptivo que narrativo. El Gonzalo de Oyón, en cambio, es épico casi siempre, y sus figuras centrales, don Alvaro y don Gonzalo, son precisas, plásticas, que se ven y se tocan y tienen contornos bien destacados; aun a pesar de que, en algunas ocasiones, se ven como Tabaré envueltas en luces dé orden sobrenatural.

La cautiva de Echeverría, "leyenda trivial en la concepción, pobre y apenas rasguñada en la forma"-como opina José Enrique Rodó-, es nada más que un bosquejo en el cual la acción dramática vale muy poco, aun si se la compara con sus descripciones, que no tienen la fuerza bravía de las famosas del Martín Fierro. El autor de La cautiva carecía de genio épico y su leyenda,-que tiene algunos méritos indiscutibles - es, como narración épica, bastante inferior al Gonzalo de Oyón, cuyo autor no sólo poseía ese genio, sino que lo expresaba, y no sólo en sus poemas, con la pluma, sino 
en la vida, con su espada de caudillo invicto, en la época más animada, dramática y guerrera en la existencia de su patria colombiana.

Verdad es que Arboleda, en ocasiones, trae a su poema reflexiones e ideas (¿frías, señor Cejador y Frauca?) de orden ético, social, político y teológico, que interrumpen la acción a veces y otras disminuyen el tempo de su movimiento. En cambio, en la narración, y en la descripción, el poema supera en brío, en fuerza épica, en objetividad y en colorido a todos los demás ensayos americanos del Siglo XIX.

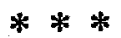

Grande lástima fué que Arboleda, el poeta soldado, no hubiese podido dejarnos concluído su Gonzalo de Oyón. Noble, culto, entusiasta, inteligente y dotado de viva imaginación, don Julio quiso dejar en su obra su propia filosofía de la conquista de América por los españoles, y quiso señalar para siempre el destino del Nuevo Mundo, que entreveía en el Misterio, gracias al dón poético supremo de su intuición... Empero, don Julio nació y vivió bajo el Signo de América, y su poema, como él mismo, nos quedó mutilado, y en sus octavas clásicas, $\mathrm{y}$ en sus bermudinas musicales, sólo percibimos el trágico aliento que anima el Continente de la libertad. El Continente que anhela vivir en orden y bajo el imperio de la ley, sin renunciar a los fueros eternos del individuo $\mathrm{y}$ del espíritu.

$$
\begin{aligned}
& \text { Carlos García-Prada, } \\
& \text { University of Wasbington, } \\
& \text { Seattle, Wash. }
\end{aligned}
$$

\section{OBRAS CONSULTADAS .}

Arboleda, Julio: Acentos republicanos (Discursos). Popayán, 1850. Ed. Bogotá, Biblioteca Popular, No 96. Al Congreso Granadino (Discurso). Popayán, 1851. 
A los señores editores de "La Gaceta", "El Neogranadino" y "El Conservador". Bogotá, 1850.

$A$ suts compañeros de armas. Popayán, 1856.

Gonzalo de Oyón (Fragmentos). Bogotá, Imp. de la Nación, 1856.

Ed. Bogotá, Biblioteca Popular, núms. 97 a 99 bis, 1917.

Guerra con el gobierno del Ecuador. Popayán, 1854.

Los Jesuitas. Bogotá, Imp. de Sánchez Caicedo y Cía., 1854.

El Misóforo. Popayán, Imp. de "El Día", 1850.

Poesías. Bogotá, Librería Ameticana y Española, 1883.

Poesias. Colección formada sobre los manuscritos originales, con preliminares biográficos y críticos por M. A. Caro. Nueva YorkAppleton, 1884.

Ed. París, 1890.

Los tres candidatos para la presidencia de la Nueva Granada. Bogotá, Imp. de N. Gómez, 1845.

Visita del General Tomás Cipriano de Mosquera a Popayán. Bogotá, Imp. de la Universidad, 1854?

Barrera, Isaac J.: J. A., en Historia de la literatura bispanoamericana. Quito, 1935, pp. 353-359.

Caro, Miguel Antonio: "Gonzalo de Oyón", en Obras completas, t. iii, pp. 414-431. Bogotá, Imp. Nacional, 1918-1928.

Id., "Noticias biográficas de J. A.", en id., pp. 372-413.

Castellanos, Joan de: sobre la rebelión de Alvaro de Oyón, en Elegías de varones ilustres de Indias, Parte III, Bibl. de Autores Españoles de Rivadeneyra, t. iv. Madrid, 1847.

Cejador y Frauca, Julio: J. A., en Historia de la lengua y de la literatura castellana, t. vii. Madrid, 1917.

Fernández de Piedrahita, Luchas: sobre la rebelión de Alvaro de Oyón, en Historia general de las conquistas del Nuevo Reino de Granada, libro xii, cap. viii. Amberes, J. B. Verdussen (1688).

Ed. con prólogo de don Miguel Antonio Caro y una noticia biográfifica por Joaquín Acosta. Bogotá, Imp. de M. Rivas, 1881.

García-Prada, Carlos: J. A., en Antología de liricos colombianos, t. i, Bogotá, 1937.

Gómez Restrepo, Antonio: J. A., en La literatura colombiana. Bogotá, Ediciones Colombia, 1926.

González Palencia, Angel: Ed. El discurso de Drake. Madrid, 1921.

Holguín y Caro, Hernando: Discurso en el centenario de J. $A$., en "Biblioteca Aldeana de Colombia", t. 73. Bogotá.

Menéndez y Pelayo, Marcelino: J. A., en Antología de la poesia bispanoamericana. Madrid, 1893.

Id. en Historia de la poesía bispanoamericana, Madrid, 1913.

Ortega, José J.: J. A., en Historia de la literatura colombiana. Bogotá, 1934.

Ed. Bogotá, 1935. 
Otero Muñoz, Gustavo: Semblanzas colombianas, J. A., en t. ii. Bogotá, 1938.

Oyuela, Calixto: J. A., en Antologia poética bispanoamericana, t. ii, vols. i y ii. Buenos Aires, 1919.

Réclus; Eliseo: La poésie et les poétes dans l'Amerique espagnole. $\mathrm{Pa}-$ ris, 1864.

Rubió y Lluch, Antonio: J. A., en Estudios bispanoamericanos. Bilbao, 1923.

Samper, José María: J. A., en Galería de bombres ihustres o notables, t. i. Bogotá, Imp. de Zalamea, 1879.

Sánchez, Luis Alberto: J. A., en Historia de la literatura bispanoamericana. Santiago de Chile, Editorial Ercilla, 1937.

Torres Caicedo, J. Maria: J. A., en Ensayos biográficos y de critica literaria sobre los principales poetas y literatos bispanoamericanos, $t$. ii. París, 1863-1868.

Valencia, Guillermo: Discurso en el centenario de J. A., en Cromos, t. 4. Bogotá, 1917.

Valera, Juan: Cartas americanas. Madrid, 1889.

Id. Nuevas cartas americanas. Madrid. 